\title{
AUTONOMIA E PARÂMETROS EXTERNOS: INCOMPATÍVEIS? RECOLOCANDO A QUESTÃO NO ÂMBITO DO LABORATÓRIO DE AVALIAÇÃO DO MOODLE, NA COMPANHIA DE WITTGENSTEIN
}

\section{Paulo OLIVEIRA*}

Da compreensão pela linguagem faz parte não apenas um acordo nas definiçóes, mas também (por estranho que pareça) um acordo nos juízos. Isso parece abolir a lógica, mas não o faz. - Uma coisa é descrever os métodos de medição, uma outra é obter e exprimir os resultados da medição. Mas aquilo que chamamos de "medir" é determinado também por uma certa constância nos resultados. (WITTGENSTEIN, 2009, p.94-96)

- Resumo: Retomo aqui a filosofia tardia de Wittgenstein e sua concepção de linguagem para refletir sobre alguns conceitos e papeis centrais no ensino de línguas, não raro tratados de forma dicotômica: autonomia vs. parâmetros externos, foco no aluno vs. professor, ensino presencial vs. plataformas eletrônicas, subjetivismo vs. transparência/objetividade na avaliação. Como freio a eventuais excessos de métodos didáticos ou modelos explicativos generalizantes, proponho a perspectiva concreta do professor na busca de soluçóes efetivas para interferir no processo de aprendizagem. Mostro então como essa atitude se expressa no fomento da escrita em cursos básicos de alemão com o material didático Blaue Blume, utilizando para isso o Laboratório de Avaliação do Moodle. Também são discutidos alguns detalhes técnicos e opçóes de uso e ajustes dessa ferramenta.

- Palavras-chave: Autonomia. Norma. Escrita. Avaliação interpares. Plataformas eletrônicas. Wittgenstein.

\section{Introdução}

Nos últimos 15 anos, tenho atuado de modo sistemático em três áreas que tradicionalmente guardam pouca intersecção institucional, teórica ou metodológica:

\footnotetext{
* UNICAMP - Universidade Estadual de Campinas. Centro de Ensino de Línguas. Campinas - SP Brasil. 13083-970 - olivpaulo@gmail.com.
} 
1 - ensino de línguas estrangeiras (alemão), com interesse sobretudo em questôes envolvendo a autonomia do aprendiz e o uso de tecnologia, notadamente com ferramentas de apoio ao ensino semipresencial e a distância (plataformas eletrônicas); 2 - teoria da tradução, do ponto de vista de abordagens antiessencialistas, culturalistas ou sociológicas; 3 - filosofia da linguagem, transitando entre a tradição hermenêutica alemã, o pós-estruturalismo e a terapia filosófica do último Wittgenstein. Mais recentemente, a atuação nessa última área levou-me também a tratar de questóes que dizem respeito mais diretamente à filosofia da educação. O presente trabalho reflete esse amálgama e apresenta uma estrutura certamente pouco comum na linguística aplicada, área na qual percebo certa dominância de dois tipos de abordagem: por um lado, análises baseadas em levantamentos empíricos com vistas a testar determinadas hipóteses, seja pela via quantitativa ou qualitativa/etnográfica; por outro, resenhas ou desenvolvimentos de modelos teóricos bastante abstratos, que procuram dar conta dos processos de ensino/aprendizagem de forma muito ampla. Em ambos os casos, tem-se uma visada marcadamente científica, envolvendo a formulação de hipóteses e sua verificaçáo, o acúmulo de conhecimento e/ou a combinação de diferentes aportes para a consolidação ou superação de determinados paradigmas teóricos. Minha visada neste trabalho, por outro lado, tem um caráter mais filosófico, que busca não o acúmulo de conhecimento, mas antes o aprofundamento da discussáo de determinadas questôes, retomando-as por diferentes ângulos. Não procura "provar" nada com base em dados empíricos nem afirmar a superioridade de determinado paradigma teórico-científico, propondo antes uma reflexão que mostra a plausibilidade de certa visão de linguagem, radicalmente pragmática e antiessencialista, assim como o caráter constitutivo dessa dimensão básica, epistêmica, para quaisquer teorias explicativas que possam ser elaboradas. Em sendo tributária da terapia filosófica wittgensteiniana, guarda também grande proximidade com aquilo que fazemos na prática concreta, procurando antes descrever essas práticas e elucidar os princípios que as norteiam, mas não explicá-las com uma fundamentação teórica a priori. É essa proximidade com a práxis concreta, tornada uma postura diante dos diferentes objetos de pesquisa, o que permite transitar entre os diferentes domínios mencionados acima. Daí advém, para o campo específico do ensino de línguas, uma preocupaçáo claramente pedagógica, no sentido de averiguar as possibilidades e os limites da intervenção didática no processo de aprendizagem. Em outras palavras: aqui, prevalece o ponto de vista do professor que quer aprimorar sua atuação no âmbito de suas competências.

Desenvolvo meu argumento em diferentes passos. No primeiro, situo a pertinência do problema para uma reflexáo sobre o ensino/aprendizagem de línguas e apresento exemplos de como a questão se coloca sob a perspectiva de diferentes modelos teóricos e em diferentes campos de aplicação, com foco sempre na questão central, i.e., sem querer discutir tais modelos em toda sua amplitude, nem sua relação mais geral com a prática. $\mathrm{O}$ que está em jogo é sempre um aspecto 
específico dessa relação teoria/prática. Na sequência, recupero um caso que nos permite ver como certas questôes são retomadas ao longo do tempo, ainda que com diferentes roupagens. Por fim, entro na discussão das práticas pedagógicas com o uso de ferramentas eletrônicas, tópico que suponho ser o de maior relevo para o leitor da revista. É possível passar mais rapidamente pela discussão conceitual e concentrar-se sobretudo na última parte de texto, notadamente se já houver familiaridade com o assunto em pauta e o interesse recair sobre questóes metodológicas, de implementação. Uma compreensão mais aprofundada do que está em jogo, por outro lado, certamente se beneficiará da discussão anterior, por mais que essa possa parecer árida ou opaca a quem náo estiver familiarizado com esse estilo argumentativo. Procurei evitar preciosismos terminológicos e espero com isso ter tornado a parte conceitual não apenas acessível como quiçá prazerosa para aqueles que gostam de perceber ligaçóes inusitadas entre campos de conhecimento que nossa academia insiste em compartimentalizar.

\section{Foco no aprendiz ou no professor}

Em sua contribuição ao XV Congresso Latino-americano de Germanística, Karen Schram (2014) lembrou que, desde a década de 1980, o foco maior da discussão sobre ensino/aprendizagem de segunda língua (L2) - e agreguemos, de língua estrangeira (LE) - tem recaído sobre o aprendiz, sendo mais recente a retomada do interesse pelo professor como agente desse processo. Projetos como o Europäisches Portfolio für Sprachlehrende in Ausbildung (NEWBY et al., 2008) ou o European Profiling Grid (CIEP, 2013) representariam essa retomada, que poderia ser lida como uma espécie de movimento pendular típico da área, com volta a temas que pareciam superados, tratando-os, no entanto, sob uma nova perspectiva. Nesse sentido, há uma dinâmica de diferenciação ou aprofundamento da discussão a cada retomada, a qual poderíamos descrever como uma espécie de espiral centrada num eixo vertical, em que não passamos pela mesma superfície ao recobrir o mesmo ponto sobre o círculo projetado na horizontal - os diferentes temas tratados.

Faço neste artigo um movimento semelhante, tendo como foco a autonomia do aprendiz e suas possíveis relaçóes com parâmetros externos - notadamente o papel do professor no fomento dessa autonomia. A discussão é sobretudo conceitual e, como aludido acima, busca inspiração num autor pouco conhecido e praticamente não debatido na área, o filósofo austríaco Ludwig Wittgenstein, cuja concepção de linguagem na obra tardia, por outro lado, está indiretamente na origem de alguns conceitos centrais para a pedagogia de línguas nas últimas décadas (ainda que isso não seja de conhecimento geral). O lócus contemporâneo de meu interesse está na ferramenta Laboratório (de Avaliação) da plataforma eletrônica Moodle, cuja inspiraçấo metodológica é de base reconhecidamente sócio-construtivista. Os exemplos fornecidos remetem à prática pedagógica corrente como professor 
de alemão no Centro de Ensino de Línguas (CEL) da Unicamp, não tendo sido desenhado nenhum experimento específico para esse fim, sendo a documentaçáo eventualmente existente decorrência do sistema de registro eletrônico da própria plataforma Moodle.

Embates teóricos levam não raro a alguns excessos que acabam por descartar como irrelevantes aspectos importantes ou centrais dos paradigmas que os novos modelos pretendem substituir, sendo que, como já reconhecia Thomas Kuhn (1997) em sua discussão inaugural da própria noção de paradigma na ciência, é comum que novos modelos simplesmente não deem conta de modo adequado de questóes bem resolvidas nos paradigmas anteriores. ${ }^{1}$ Esse descompasso certamente faz parte das forças que levam ao movimento pendular a que se refere Schramm e que professores de língua estrangeira "com mais tempo de estrada" conhecem bem, com base nas diferentes "ondas" metodológicas que surgem de tempos em tempos. Tais mudanças de foco devem ser encaradas com naturalidade, portanto. Mas um problema real se coloca com a questáo dos excessos das abordagens que se querem inovadoras, sobretudo quando assumem ares dogmáticos que não permitem a resolução ou quiçá nem mesmo o reconhecimento de dificuldades concretas que se colocam na aplicação dos novos modelos propostos, identificando qualquer crítica aos novos paradigmas como um apelo à retomada dos anteriores, tidos por superados.

É certamente isso o que ocorre, por exemplo, numa certa vertente do construtivismo aplicado ao ensino de língua materna, como descreve muito bem Villalobos (2014) em sua crítica ao programa Ler e Escrever da Prefeitura Municipal de São Paulo. Numa análise minuciosa de vários aspectos do programa, a autora mostra que o apego excessivo e simplificador ao modelo alfabetizaçáo e letramento proposto (psicogênese da língua escrita, de Ferreiro e Teberosky) praticamente transforma em anátema qualquer forma de instrucionismo, i.e. de intervenção direta do professor na explicitaçáo de regras. Destaquemos alguns trechos exemplares dessa crítica:

As “intervençôes" previstas mostram que não é relevada a possibilidade de qualquer tipo de intervenção explícita, por exemplo, sobre o valor sonoro de uma letra, ou sobre como ela se junta com outra para formar o som de uma sílaba. A premissa

\footnotetext{
No nível epistêmico mais geral, a noção de paradigma remete a uma discussão inaugurada por Wittgenstein: "Aquilo que, aparentemente, deve existir, pertence à linguagem. É um paradigma no nosso jogo; algo com o quê se fazem comparaçóes. E isso pode ser uma observaçáo importante - mas continua a ser uma observação que diz respeito a nosso jogo de linguagem, nossa forma de apresentação" (WITTGENSTEIN, 2009, p. 28-29 [IF, $\$ 50$ ]). De modo complementar ao sistema de referências padrão da revista, agreguei [entre colchetes] as siglas e indicaçôes de seção comumente usadas pelos comentadores do filósofo, procedimento que visa facilitar a utilização de diferentes ediçóes para consulta. A referida noção de paradigma é central para o conceito wittgensteiniano de gramática e sua distinção entre os usos normativo e descritivo da linguagem (WITTGENSTEIN, 2006 [CV]; 2009 [IF]). Não cabe aqui aprofundar essa discussão, mas ela é certamente relevante para os tópicos em pauta. São de minha responsabilidade as traduçôes cujos autores não constem nas referências bibliográficas.
} 
que orienta estas "intervençóes" é de que a criança só conseguirá aprender aquilo que descobrir sozinha por meio de "reflexão" e de "elaboração de hipóteses" (VILLALOBOS, 2014, p.74).

[...] o papel do professor fica quase que totalmente reduzido à apresentação das atividades e exortaçóes para a reflexão do aluno, pois só a própria reflexão independente da criança lhe permitirá compreender o objeto a ser aprendido, como se qualquer descrição ou explicação do professor sobre a natureza e o funcionamento do objeto pudesse comprometer todo este processo (VILLALOBOS, 2014, p.109).

Um dos corolários dessa postura que aposta no foco no aprendiz como modelo único e suficiente é, como aponta a autora, uma exclusão da autonomia do professor para escolher os métodos de trabalho adequados para as diferentes situaçóes (VILLALOBOS, 2014) e, no limite, uma negação do próprio papel do professor como mediador no processo de aprendizagem.

Indo um pouco além dos tópicos destacados por Villalobos, pode-se concluir que a proposta em tela toma a aquisição natural da língua como modelo exclusivo, desconsiderando que a escrita envolve técnicas complexas com alto grau de convencionalidade - no que difere fundamentalmente da oralidade, em vários aspectos que não cabe aqui aprofundar. De resto, propostas como essa também passam ao largo do fato de que, como já apontava Wittgenstein em seu último texto, $D a$ Certeza, a própria aprendizagem natural - do que quer que seja - se dá em grande parte pela via da aceitação tácita da autoridade de outrem: "A criança aprende acreditando no adulto. A dúvida vem após a crença $[\$ 160]$. Aprendi uma enormidade aceitando a autoridade humana e depois obtive a confirmação ou invalidação de certas coisas através de minha própria experiência [\$ 161]" (WITTGENSTEIN, 1975, p.23-24 [DC, $\$ \$ 156-167])$. A questão se complica ainda mais quando o que está em jogo é a explicitação da norma que subjaz a determinado jogo de linguagem ou, em outras palavras: quando não se percebe a diferença fundamental entre a preparaçáo para o jogo, com a explicitação das normas e regras etc., e o jogo em si, jogado segundo as referidas normas e regras. Que a explicitação de certas regras se dê não raro quando o jogo já está em curso, ou que elas sejam aprendidas de modo implícito na prática constante (WITTGENSTEIN, 1982 [UE]), certamente não torna fácil a percepção dos diferentes momentos. Mas uma pedagogia que se queira eficiente terá de aprender a diferenciá-los.

Um risco semelhante ao da recusa a qualquer forma de instrucionismo explícito, como no construtivismo do programa Ler e Escrever comentado por Villalobos (2014), pode ser encontrado num polo praticamente oposto da discussão contemporânea, a saber, na perspectiva do "pós-método" no ensino de L2/LE, na medida em que, ao mesmo tempo em que se postula a necessidade de levar em conta o contexto específico da sala de aula em toda sua complexidade, reconhecendo não haver um "método" único 
aplicável a todas situaçóes e reconhecendo com isso o papel fundamental do professor na busca por soluçóes adequadas, certas características dos modelos teóricos acabam sendo transpostas para o ecossistema da sala de aula de modo quiçá excessivo. Em sua resenha do tópico, Borges e Paiva (2011, p.350) consideram que, ao "centrar-se no processo de aprendizagem e de desempenho dos alunos", uma abordagem complexa de ensino deve, dentre outros, considerar também

[...] organizar-se na coconstruçáo (professor-alunos) de um planejamento semiótico-ecológico de ensino de língua, cujo eixo forma-significado-uso (normatividade linguística, van Lier, 1996) exerça uma força centrípe[t]a e; o eixo autonomia-autenticidade-consciência desempenhe uma força centrífuga (criatividade linguística, van Lier, 1996) no desenvolvimento da lingua(gem). (BORGES; PAIVA, 2011, p.352).

Tal exigência remete à apropriação bakthiniana de alguns conceitos da física, segundo a qual uma linguagem unitária, individual, constitui-se como "força centrífuga" numa luta para superar a heteroglossia que, por sua vez, age como "força centrípeta" centralizadora do pensamento verbal-ideológico e núcleo linguístico estável (CLARK; HOLQUIST, 1998, p.103). No célebre "argumento da linguagem privada" desenvolvido nas Investigaçóes Filosóficas, Wittgenstein, por sua vez, descarta a possibilidade de uma linguagem feita para uso interno, sem recorrer a um modelo de uso público (WITTGENSTEIN, 2009, p.95-111 [IF, \$\$ 243-315]). Nisso, sua visada afasta-se radicalmente da tradição filosófica ocidental, em que essa possibilidade não é descartada (GLOCK, 1998). Isso não significa que Wittgenstein não reconheça o papel do indivíduo na modificação ou criação de novos jogos de linguagem, tópico de outra célebre passagem das Investigações (WITTGENSTEIN, 2009 [IF $\$ \$ 23-25]$ ), numa discussão que claramente antecede a teoria dos atos de fala desenvolvida por Austin (e Searle). Num certo sentido, tanto Bakthin quanto Wittgenstein convergem aqui com uma preocupação dos românticos alemães, que já no sec. XIX reconheciam a tensão entre o próprio e outro na linguagem, como sintetizou Schleiermacher em sua clássica conferência sobre Os dois métodos de traduzir, proferida em 1823:

Ele [todo homem] não pode pensar com total determinação nada que esteja fora dos limites da sua língua. A configuração dos seus conceitos, o tipo e os limites das suas articulaçôes são previamente traçados para ele pela língua em que nasceu e foi educado; o entendimento e a fantasia estáo ligados por ela. Por outro lado, porém, cada [todo] homem de livre pensar e espiritualmente espontâneo molda também a língua. [...] Nesse sentido, portanto, é a força viva do indivíduo que produz novas formas na matéria maleável da língua. (SCHLEIERMACHER, 2010, p.49). 
Estamos aqui diante da antiga questão da existência da norma (por si conservadora) em oposição à capacidade de inovaçáo inerente à linguagem, a qual, no limite, leva à dinâmica de mudança da/na língua - com efeito, inclusive, sobre as próprias normas (no longo prazo). Mas, em que medida isso se aplica a um contexto de ensino/ aprendizagem de língua estrangeira, mais ainda em situação de sala de aula? Significaria que as construçóes ad hoc dos alunos devam ser consideradas como equivalentes, enquanto fator de mudança da língua, às inovaçóes dos falantes nativos - notadamente em seus contextos originais, em situação de imersão? Não se estaria assim colocando interlíngua (nível do sujeito aprendiz), hibridizaçáo (fenômeno social de culturas em contato) e dinâmica linguística (característica geral da linguagem) num mesmo patamar? Aqui, corre-se o risco de atribuir ao universo da sala de aula a capacidade de criar normas cuja aceitabilidade possa ser fundamentada pelo fato de que o conhecimento, de modo geral, é socialmente construído - como se a construção de certo consenso ou padráo comunicativo no interior da sala de aula fosse, por si só, suficiente para conferir a tal padráo uma aceitabilidade mais geral. Talvez não seja isso necessariamente o que se postula no planejamento semiótico-ecológico, tal como resenhado por Borges e Paiva (2011). Mas é importante estarmos atentos para os riscos desse tipo de leitura, que transporia de modo excessivo elementos do modelo teórico para as situaçóes reais, impingindo à realidade características do modelo. ${ }^{2}$

Se olharmos para o que acontece fora da sala de aula, não será difícil perceber que a própria dinâmica da linguagem possui mecanismos que inibem o excesso de inovação - até porque toda língua, para ser efetiva, depende de uma certa estabilidade. Em entrevista para o Jornal da Unicamp, sobre o primeiro volume da Gramática do Portugues Culto Falado no Brasil, Ataliba Castilho resume:

A língua culta é muito pesadona, redundante, e tem um dinamismo menor. A língua popular é mais livre, mais criativa, e acaba por ter uma gramática mais sofisticada, como no caso da [falta de] concordância verbal [explícita] mencionada. Isso ocorre mais na questão da organização gramatical da sentença e na construçáo das palavras. A gramática da língua culta reflete o passado. A gramática da língua popular aponta para o futuro da língua, e toma soluçóes novas com mais frequência. Mas é claro que na exposição das ideias, na argumentação, a língua culta leva vantagem. A falta de cultura letrada parece dificultar a elaboração do argumento, frequentemente abandonado no meio do caminho. [...] O trabalho da escola é promover o cidadão. E como é que o cidadão vai ser promovido se ele náo tiver à sua disposição o modo de falar de pessoas de uma outra classe, de um outro nível? [...] A escola deve fazer do cidadão um "bilíngue" em sua própria língua, por assim dizer. Assim ele poderá graduar sua fala. [...] Para cada

\footnotetext{
2 É desse tipo de postura que a filosofia tardia wittgensteiniana faz a terapia, aplicando-a inclusive ao próprio dogmatismo da obra de juventude (WITTGENSTEIN, 2009 [IF \$ 107]).
} 
situação, há portanto uma modalidade linguística adequada. Todo o lance será, por meio do ensino escolar, levar o aluno a conhecer a variedade que ele náo domina familiarmente, que é justamente a variedade dominada em outro meio. (CASTILHO, 2006, p.4-5).

Destaquemos alguns aspectos do trecho citado. $\mathrm{O}$ primeiro deles é que existem diferentes modalidades e registros, com certa autonomia entre si. $\mathrm{O}$ fato de que a língua popular, no registro oral, é mais dinâmica e inovadora, não significa que tais inovações transformem-se facilmente em novas normas de aplicação geral, muito menos no registro escrito. Se a falta da cultura letrada dificulta a construção do argumento, é função da escola dar acesso a essa cultura letrada (sem com isso necessariamente estigmatizar a linguagem popular), com todas as peculiaridades de suas normas. E essa cultura letrada é mais conservadora, é um freio que garante aquele grau de estabilidade necessário ao funcionamento da língua como veículo de comunicação e coesão social (dentre vários outros aspectos). Isso significa que a "força centrípeta" da linguagem não poderá ter um alto grau de eficácia no contexto da sala de aula, menos ainda em se tratando do ensino de LE.

Nesse último aspecto, é salutar observarmos o que ocorre em comunidades relativamente fechadas, como no caso de grupos de imigrantes que cultivam a língua do país de origem em sua comunicação mais imediata. Por mais que sejam permeáveis às influências do contato com a língua majoritária, como atesta o misturado praticado em colônias alemãs no sul do Brasil, tais línguas ou dialetos são altamente conservadores no tocante a seu funcionamento interno. É notório que linguistas interessados no dialeto do Hunsrück, região localizada no estado da Renânia-Palatinado, no sudoeste da Alemanha, vêm frequentemente estudar o Hunsrückisch falado nos estados brasileiros de Santa Catarina, Rio Grande do Sul, Paraná, São Paulo (municípios de São Roque e Mairinque) e Espírito Santo (municípios de Marechal Floriano e Domingos Martins) - exatamente porque essas variantes estão mais próximas da língua de comunicação quando da imigração para o Brasil, na década de 20 do séc. XIX (dados geográficos extraídos da Wikipédia). Para nossa discussão, importa ressaltar que tal conservadorismo guarda um paralelo com a situação do ensino de LE, na medida em que o parâmetro externo ao ecossistema específico é fundamental para a constituição do objeto. O descendente de imigrantes quer preservar sua identidade familiar "de alemão"; o aprendiz de alemão na universidade brasileira quer adquirir os modelos de comunicação "da Alemanha" (ou "da Áustria, Suíça” etc.). Por mais que se pratique uma linguagem, em sala de aula, que contemple algumas características de hibridização, como um uso mais frequente de palavras de origem latina (para aumentar a compreensibilidade), um padrão de pronúncia necessariamente mais tolerante ao sotaque brasileiro etc., o objetivo de aprendizagem está ligado necessariamente a um grau de domínio compatível com parâmetros externos, dos países em que a língua-alvo é o padrão. 


\section{O Dicionário ortográfico para escolas primárias de Wittgenstein}

No breve período em que foi professor primário em regiôes remotas da Áustria, o jovem Ludwig Wittgenstein deparou-se com questóes semelhantes às discutidas na seçáo anterior. Convicto de ter resolvido "todos os problemas da filosofia" com seu Tractatus Logico-philosophicus (WITTGENSTEIN, 1961 [T]), o pensador austríaco encerrou suas atividades universitárias em Cambridge para retornar à terra natal, no início da década de 20 do século passado, disposto a abandonar de vez as preocupaçóes mundanas e da academia. Após trabalhar por algum tempo como jardineiro em um convento, decidiu abraçar a carreira didática num momento em que era implementada a reforma escolar austríaca, destinada a formar cidadãos autônomos e democráticos, por oposição ao conservadorismo do período imperial. Apesar de participar ativamente desse movimento e aderir a vários de seus princípios, Wittgenstein fazia-lhes também algumas ressalvas, sobretudo no tocante à concepção de educação em jogo. Fernanda Reis $(2015$, p.2) lembra que a reforma de ensino conduzida na Áustria republicana do pós-guerra por Otto Glöckel enfatizava a "participação ativa dos alunos" e a "doutrina de aprender fazendo", as quais possibilitariam aos alunos "descobrir as regras por seu próprio esforço". Nesse espírito, as redaçóes deveriam ser "escritas livremente, sem atenção especial à ortografia e à gramática”. A autora lembra também que Wittgenstein "não tinha a expectativa de preparar seus alunos para a vida democrática e não acreditava que as mudanças sociais e políticas pudessem ocorrer a partir de movimentos escolares", servindo antes apenas para "mostrar às pessoas o valor da realização intelectual em si e também do trabalho manual que exerciam", enfatizando dessa forma a "relevância do aprimoramento pessoal" (REIS, 2015, p.3).

Tanto a adesão a certos aspectos da reforma escolar austríaca quanto as ressalvas citadas por Reis ficam evidentes na decisão do então professor primário, de elaborar um Dicionário ortográfico que servisse de apoio a seus alunos nas redaçóes. ${ }^{3}$ Contrariando a orientaçáo de que as redaçôes deveriam ser "escritas livremente, sem atenção especial à ortografia e à gramática” (REIS, 2015, p. 3), e a de que os alunos deveriam consultar seus pares no momento da revisão, Wittgenstein assume a perspectiva do professor determinado a intervir no processo, conforme explicitado logo no início do prefácio:

O presente dicionário tem como objetivo atender a uma necessidade urgente no ensino de ortografia nos dias de hoje. É resultado da experiência prática do autor: para aprimorar a ortografia na sua turma, pareceu-lhe necessário disponibilizar

\footnotetext{
Retomo aqui alguns aspectos de trabalho ainda inédito (OLIVEIRA, 2015), transcrevendo certos trechos literalmente ou com pequenas modificações, mas desconsiderando aspectos não pertinentes à presente discussão, os quais dizem respeito, sobretudo, às concepçôes de ética e autonomia de Wittgenstein em diferentes fases de sua obra. Na sequência, passo à discussão das possibilidades e limites da correção interpares na ferramenta Laboratório do Moodle, parte mais aplicada deste trabalho.
} 
dicionários a seus alunos, para que pudessem informar-se a qualquer momento sobre como se escreve uma palavra, porém sem ter de levantar-se; e certamente, em primeiro lugar, podendo fazer isso o mais rápido possível [...]. Sobretudo na escrita e no aprimoramento de suas redaçóes, a ortografia das palavras tornou-se um problema interessante e urgente para os alunos. Perguntar com frequência ao professor e aos colegas perturba os alunos em seu trabalho, levando a uma certa acomodação mental e, além disso, a resposta dada pelos colegas muitas vezes está errada. [...] Somente o dicionário possibilita ao aluno ser plenamente responsável pela ortografia de seu próprio texto, pois lhe fornece um meio mais seguro de descobrir e corrigir seus erros, sempre que quiser fazê-lo. É absolutamente necessário que o aluno corrija por si mesmo seus próprios textos. $\mathrm{O}$ aluno deve sentir-se como o único autor de seu próprio texto e também ser o único responsável por ele. Além disso, apenas a revisáo feita sem a ajuda do professor permite a esse elaborar uma imagem correta das capacidades e da inteligência do aluno. A troca de cadernos e a revisão mútua dos textos de colegas levam, por assim dizer, a uma imagem difusa da capacidade da turma. Não é com base no trabalho do aluno A que devo avaliar o que sabe o aluno $B$. Isso deve ser visto no trabalho de B. E a revisão mútua não fornece, como tem sido afirmado, uma imagem correta do nível geral da turma (para isso, cada aluno teria de revisar os textos de todos seus colegas, o que, naturalmente, não é possível). Creio também que ao professor náo deve interessar um conhecimento ortográfico médio, pois náo é a turma que deve aprender ortografia, mas sim cada aluno individualmente. (WITTGENSTEIN, 1977, p.XXV, tradução minha, grifo meu).

Parte dos trechos que destaquei nessa longa citação mostra uma preocupação com a aquisição de um padráo de correçáo que é externo a um eventual consenso ad hoc dos alunos, evidenciando que, para Wittgenstein, um tal padrão não teria como mobilizando aqui os termos da discussão contemporânea - emergir do ecossistema da sala de aula. Outros trechos destacados evidenciam a preocupação com o desenvolvimento da autonomia do aluno, no sentido de que esse deve assumir a plena responsabilidade por seu trabalho. Aqui, já fica claro que, numa visada wittgensteiniana, autonomia e respeito a parâmetros externos não são incompatíveis, mas sim complementares. Destaquei também alguns trechos em que o professor chama para si a responsabilidade, notadamente no tocante a uma eventual adequação aos parâmetros externos (norma de correção), mas também à necessidade de levar em conta desempenhos individuais, para entâo interferir didaticamente no processo.

Mas até que ponto os aspectos destacados no prefácio ao Dicionário invalidam o trabalho coletivo, seja no contexto de atuação do professor primário Wittgenstein, em um povoado remoto da Áustria na segunda década do século passado, seja no contexto brasileiro contemporâneo? Wittgenstein reporta que sua metodologia levou a bons resultados, na medida em que "a melhoria na ortografia foi surpreendente", 
em função de ter sido despertada a "consciência ortográfica" dos alunos (OLIVEIRA, 2015, p.13). Nesse contexto específico, com crianças do nível fundamental em atividades de revisão das próprias redaçóes, retirar a ênfase da colaboração com os colegas parece ter sido uma medida acertada. $O$ foco estava na revisáo ortográfica, algo que hoje pode inclusive ser feito, parcialmente, com a ajuda de ferramentas eletrônicas, sem recorrer aos colegas ou ao professor. Mas como ficaria, por exemplo, a consciência gramatical e textual: caberia aqui recorrer ao trabalho coletivo ou mesmo à correção interpares, como sugere a pedagogia sócio-construtivista? $\mathrm{O}$ tópico é de grande relevância, sobretudo se pensarmos nos esforços correntes no Brasil, em várias esferas educacionais, no sentido de ampliar o acesso à formaçáo. Em muitos dos programas atuais, um instrumento que vem sendo usado em grande escala é a plataforma eletrônica Moodle, de base filosófica sócio-construtivista (sendo também software livre e de código aberto). Eu mesmo tenho trabalhado intensamente no Moodle à procura de instrumentos que permitam uma implantação efetiva de trabalho coletivo, aí inclusa a avaliação interpares. Até que ponto as restriçóes feitas por Wittgenstein são relevantes para esse tipo de abordagem, em que medida as dificuldades do passado foram eventualmente superadas? A próxima seção procura investigar essas questóes com base na experiência de uso do Moodle no ensino de alemão para estudantes universitários no CEL/Unicamp.

\section{Escrita e avaliação interpares no Moodle}

A integração de uma dimensão mais horizontal e eventualmente coletiva a tarefas escritas tem sido uma preocupação minha há vários anos, desde quando trabalhava com o TelEduc (plataforma desenvolvida na própria Unicamp). Quando da migração de meus cursos de alemão para o Moodle (primeira utilização dessa plataforma na Unicamp, em caráter piloto para a universidade como um todo), passei a testar os recursos disponíveis em cada nova versão do ambiente, como as ferramentas Tarefa (Assignment) e Wiki (nesses casos, com divisão da turma em grupos de trabalho). As versôes mais recentes do ambiente implementaram o Laboratório (de Avaliaçáo), ou Workshop, ferramenta que hoje considero a mais adequada para atividades de revisão/avaliação mútua: de modo individualizado, sem necessidade da criação de grupos de trabalho. O Laboratório faz uso de um algoritmo complexo que mobiliza inteligência artificial para calcular as médias de desempenho do aprendiz, com base nas notas recebidas de um certo número de colegas, e das atribuídas por ele ao mesmo número de colegas, numa determinada tarefa de produção escrita. ${ }^{4}$ Tratase de um grande avanço, pois assim torna-se realmente viável trabalhar com um número maior de tarefas escritas, inclusive em turmas grandes (OLIVEIRA, 2012).

\footnotetext{
4 Para uma síntese gráfica referente à última versão do sistema (2.7) quando da redação deste texto, vide: $<$ https://docs.moodle.org/27/en/File:workshop_grades_calculation.png>. Acesso em:18 mai. 2015.
} 
Além disso, o professor pode e deve fornecer critérios de avaliação e até mesmo exemplos de correção com base nesses critérios. Mas o sistema, apesar de todo seu refinamento, não funciona de modo adequado só com os recursos automatizados. É interessante notar que a nota de referência calculada com base na eficácia dos avaliadores reflete uma tendência da turma, o que certamente fornece subsídios para que o professor faça as devidas intervençóes. Por outro lado, tal tendência não corresponde sempre, nem necessariamente, ao melhor uso dos critérios de avaliação fornecidos pelo professor. Aqui cabe, mutatis mutandis, o comentário de Wittgenstein em seu prefácio, de que não deve interessar ao professor um conhecimento "médio" da turma, mas sim de "cada aluno individualmente" (OLIVEIRA, 2015, p.12). E essa avaliação final só pode ser feita pelo próprio professor, que deve chamar para si tal responsabilidade, por mais que faça uso de instrumentos auxiliares, dentre os quais a avaliação interpares. Ou seja, cabe também ao professor assumir plenamente seu papel de guardião de uma certa norma de correção, ou adequação - algo que nem sempre é reconhecido na discussão pedagógica contemporânea, notadamente nas propostas mais declaradamente antinormativistas.

A ferramenta Laboratório é bastante complexa e prevê o ajuste de uma série de parâmetros que, por outro lado, dáo espaço a muita flexibilidade. Um primeiro aspecto de seu uso em meus cursos está na vinculaçáo a alguns recursos avançados do Moodle, que têm de ser ativados no nível de Administração/Gerenciamento do sistema, a saber, "acompanhamento/rastreamento de conclusão" e "atividades condicionadas". Caso essa opção não apareça nas opçóes do curso, torna-se necessário contatar o setor responsável e negociar sua ativação. A Figura 1 mostra uma tela com o uso de atividades condicionadas, sendo que, para fazer a tarefa WS03 (Laboratório da Unidade 3 no material didático), o aluno terá antes de completar a Tarefa Eletrônica (TE03: questôes formais, usualmente de vocabulário/gramática, com correção automática pelo sistema), preenchendo certos critérios de completude, como uma determinada nota parcial (porcentagem de acerto). O princípio didático por detrás desse condicionamento é de que atividades de produção são mais complexas do que as com resposta fechada e demandam um certo domínio de tópicos formais que, por esse motivo, foram transformados em pré-requisito. A tela contém ainda links para correçóes da tarefa em semestres anteriores (arquivos em formato PDF), o que permite ao aprendiz ter uma amostra das boas e más práticas de escrita e se nortear pelas primeiras. 
Figura 1 - Ambiente Moodle: atividades condicionadas

TE03

Restrições: '

- Disponivel apenas quando a atividade Sistema de avaliação for marcada como concluída.

- Não disponivel até que você atinja a nota necessária em Metodologia/Avaliação .

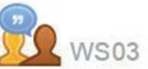

Restrições: 'Disponivel apenas quando a atividade TE03 for marcada como concluida.'

WS03_Korrektur_2-2014

Correção da tarefa desta turma.

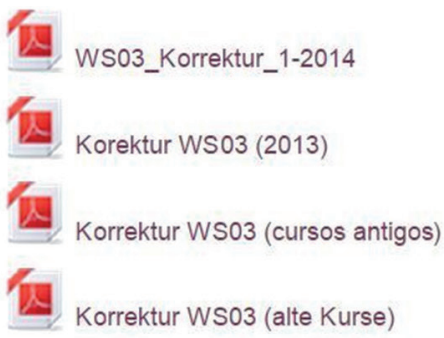

Alguns exemplos de correção em textos representativos, por amostragem (cursos antigos).

Fonte: Alemão I, 2o Semestre de 2014.

Nos ajustes do Laboratório propriamente dito, ${ }^{5}$ optei por manter anônimas todas as avaliações interpares, o que pode ser feito via recursos de Administração/Gerenciamento do site, de parte dele ou de cada Laboratório individualmente, escolhendo "não" para as opçôes de visualização para "autores" e "revisores", no papel de "estudante". Com isso, tem-se um sistema de avaliação "duplamente cego", o que possibilita o foco apenas nos conteúdos, i.e., eliminando o fator ad hominem. Também mantive desabilitada a opção de "auto-avaliaçáo", que certamente poderá ser útil em outros contextos. Usualmente, não tenho fornecido exemplos de avaliaçáo, tendo em vista a alta frequência das tarefas escritas e a possibilidade de usar correçóes de cursos antigos, feitas pelo próprio professor, com a mesma função. Uma implementação relativamente recente que facilita o gerenciamento do Laboratório é a possibilidade de agendar os

\footnotetext{
5 Descrições detalhadas e tutoriais em vídeo disponíveis em: <https://docs.moodle.org/27/en/Workshop_module>. Acesso em: 18 mai. 2015.
} 
prazos de envio e avaliação, passando de uma fase para a outra de modo automático e atribuindo, também automaticamente, determinado número de avaliadores para cada tarefa, de modo aleatório (Figuras 2 e 3, abaixo). Outros detalhes de configuração são menos relevantes para nossa discussão.

Figura 2 - Cronograma do WS

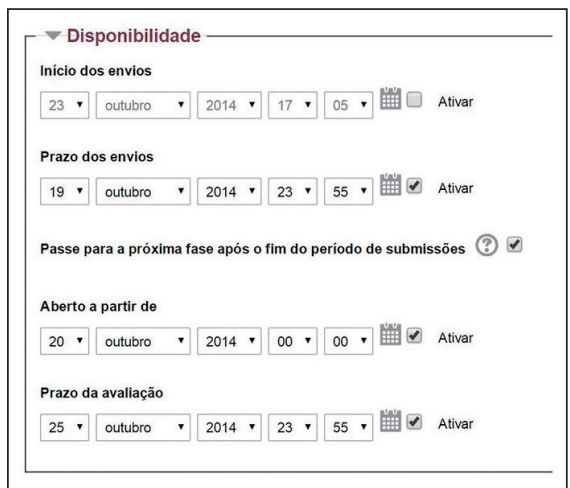

Fonte: Alemão I, 2o Semestre de 2014.
Figura 3 - Alocação automática

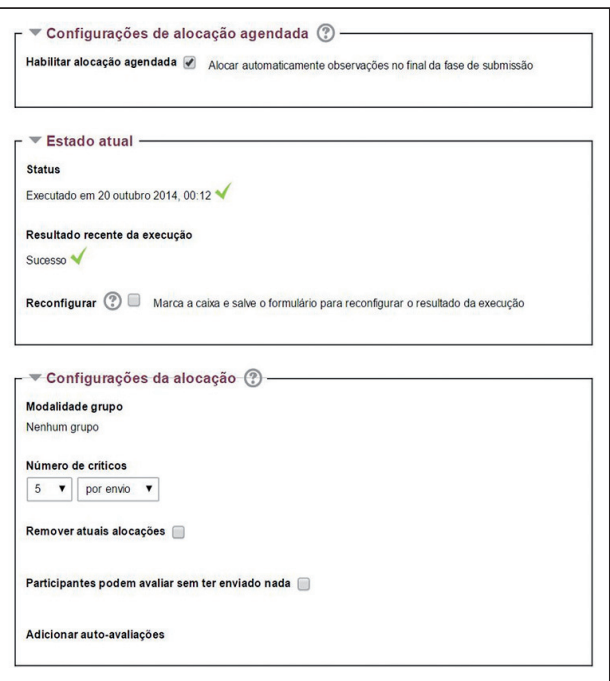

Fonte: Alemão I, 2o Semestre de 2014.

Como primeiro exemplo de avaliação interpares no Laboratório, tomemos o caso simples do uso de corretor ortográfico eletrônico, colocado por mim como exigência nas tarefas escritas. Tal exigência corresponde à expectativa de que o aluno deve lançar mão de todos os recursos disponíveis na elaboração e revisão de seus textos, assumindo plena responsabilidade pela adequaçáo dos aspectos formais. Ocorre que, talvez por influência dos tipos de textos em formato eletrônico a que estão acostumados, com registro muito solto e estilo quase oral (e-mail, anotaçóes em blogs ou no Facebook, chats), os alunos não têm o hábito de fazer revisão - ou mesmo de planejar seus textos de modo a adequá-los aos diferentes registros e gêneros letrados (funçáo do desenvolvimento da escrita em um curso de LE). Para reforçar a relevância desse tipo de ferramenta, a solução que encontrei foi atribuir-lhe um peso alto nos critérios de avaliação, de modo que sua não-utilização tivesse um impacto negativo na nota. No longo prazo, essa estratégia tem-se revelado eficaz, com diminuição de tarefas escritas sem passar por uma fase de revisão. No entanto, alguns alunos demonstram não perceber de modo adequado as limitaçóes desse tipo de instrumento, criando a expectativa de seja captado, de modo adequado, todo e qualquer desvio do padráo, náo só ortográfico, como também gramatical. Por esse motivo, no momento da avaliação 
interpares, atribuem nota baixa a textos com poucos problemas passíveis de solução via revisor ortográfico nos níveis correspondentes. Aqui, minha intervenção como professor tem sido no sentido de alertar para o potencial e, sobretudo, as limitaçóes da ferramenta, como no feed-back dado a uma turma Alemáo I no $2^{\circ}$ semestre letivo de 2014 (Figura 4, abaixo) - em termos semelhantes àquilo que, mais adiante, foi incorporado à descrição dos próprios critérios de avaliação.

A questão conceitualmente mais interessante, no entanto, reside na aplicaçáo dos critérios de avaliação fornecidos para cada tarefa. Por um lado, é certamente positivo que o professor seja obrigado a explicitar os critérios que usaria, para que os alunos possam aplicá-los não só na avaliação das tarefas de seus pares, como também na elaboração de seus próprios textos, em tarefas futuras. Com isso, prevê-se a gradativa internalizaçáo desses critérios, num processo de calibragem das expectativas dos alunos - que não raro querem elaborar algo muito mais complexo do que aquilo que é pedido. Ocorre que nem sempre o professor consegue definir a priori todos os critérios pertinentes, ou colocá-los dentro de uma relação de peso adequada. Assim, às vezes percebe que teria avaliado determinado texto de modo diferente do que os alunos, não só quando os critérios não foram bem aplicados, mas também em casos em que houve uso relativamente adequado dos critérios fornecidos, no sentido estrito de ater-se às descriçôes que constam do sistema. O Moodle fornece algumas alternativas para lidar com isso na ferramenta Laboratório. 


\section{Figura 4 - Comentários}

\section{WS03_2-2014 - Korrektur mit Kommentaren}

Toda tarefa tem um determinado foco, aquilo que está em jogo no momento. Aqui, temos uma série de detalhes que poderão eventualmente ser menos importantes em outros momentos, como, por exemplo, a grafia em maiúscula ou minúscula das nacionalidades, dependendo do contexto de uso (= maiúscula quando se refere à pessoa, cf. tabela na p. 17 do material didático). Isso não significa que esse detalhe seja indiferente em outros contextos, apenas que um eventual deslize não prejudicará a comunicação. Portanto, não deverá ser muito valorizado no momento da correção. Mas quando algo está em foco, deve receber toda a atenção. Esse é um aspecto importante nas tarefas escritas: concentre-se naquilo queé pedido no enunciado, use os modelos fornecidos!

Uma outra coisa importante nas tarefas escritas é trabalhar com planejamento e revisão. Esse aspecto será trabalhado de modo sistemático mais adiante, porém já vale a pena começar a dar-lhe a devida atenção. Aqui, novamente, pequenos detalhes podem fazer a diferença. Muitos desses detalhes podem ser detectados como simples uso de uma ferramenta de correção ortográfica, disponível nos redatores de texto e navegadores, bastando para isso instalar os complementos necessários, que não raro são gratuitos. As duas telas abaixo mostram como fica o mesmo trecho com marcações do corretor ortográfico do Word e após as correções pelo professor.

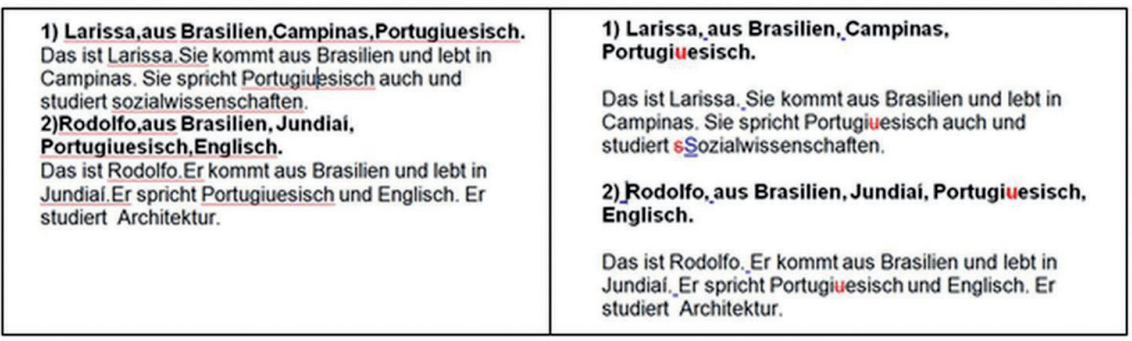

Notem-se os detalhes da correção: 1) inserção de espaço após pontuação, o que é uma convenção da escrita; 2) grafia da palavra Portugiesisch; 3) uso de maiúscula no substantivo Sozialwissenschaften. 0 último detalhe, por exemplo, é uma das regras mais gerais do alemão e, portanto, uma das mais produtivas no momento da leitura, como enfatizado em sala de aula. É natural que nos esqueçamos desse detalhe na hora de escrever, que num ou noutro caso grafemos com minúscula. O texto acima é um exemplo disso. Aqui, um corretor ortográfico eletrônico poderia apontar esse problema já na fase de redação/revisão. O mesmo se aplica à questão dos espaços após pontuação. Isso não significa que o corretor ortográfico dê conta de tudo: às vezes, a grafia é apontada como correta, mas se refere a algo diferente (outra forma verbal, por exemplo); às vezes, é apontada como incorreta, porque o termo não está na base de dados - apesar de existir. Nesses casos, para-se para pensar, consulta-se o livro etc.

Em tempo: na tarefa acima, faltou a primeira parte, dos diálogos. Os colegas levaram isso em conta na avaliação interpares, de modo adequado.

Fonte: Alemão I, 2o Semestre de 2014.

A Figura 5 (abaixo) traz alguns exemplos dos tipos de intervenção possíveis, numa tela parcial da avaliação interpares do Laboratório WS31 (Alemão IV, $1^{\circ}$ semestre letivo de 2014). Na primeira linha, percebe-se uma intervenção moderada do professor, com alteração da nota recebida de 53 para 57/60 - de modo direto. Trata-se aqui de um daqueles casos em que a aplicação dos critérios, pelos alunos, foi excessivamente 
rigorosa. Na terceira linha, percebe-se algo semelhante, com uma alteração bem mais significativa: de 29 para 40/60. Na quarta linha, foi dado um peso maior (3) para a avaliação mais eficiente, de modo a obter-se um resultado geral mais condizente com o espírito dos critérios fornecidos. Por esse motivo, a intervenção do professor não vem grafada de modo direto, via substituição das médias. Ao lado das notas, o sistema fornece, entre parênteses, a média obtida por cada aluno na condição de avaliador. No exemplo citado, tem-se um avaliador com nota máxima nessa condição (40/40) e outros dois menos eficazes $(34 / 40 ; 32 / 40)$. Independentemente do tipo e da radicalidade da intervenção, há sempre a possibilidade de se dar retorno circunstanciado ao aluno, seja na condiçáo de autor ou avaliador dos textos. Nos casos em tela, não houve impacto nas médias obtidas na condição de avaliador (última coluna da direita), o que também poderia ocorrer. Em princípio, os melhores avaliadores têm também o melhor desempenho na parte de produção; inversamente, quem ainda não domina os tópicos da tarefa terá maior dificuldade em aplicar os critérios de avaliação, que ainda não foram internalizados. Coloca-se também a questão dos alunos que não fazem todas as avaliaçóes previstas, o que prejudica o cálculo das notas. Uma medida possível, nesses casos, é cortar proporcionalmente a nota como avaliador (o que o sistema não faz de maneira automática).

Figura 5 - Intervenções nas notas do Laboratório WS31

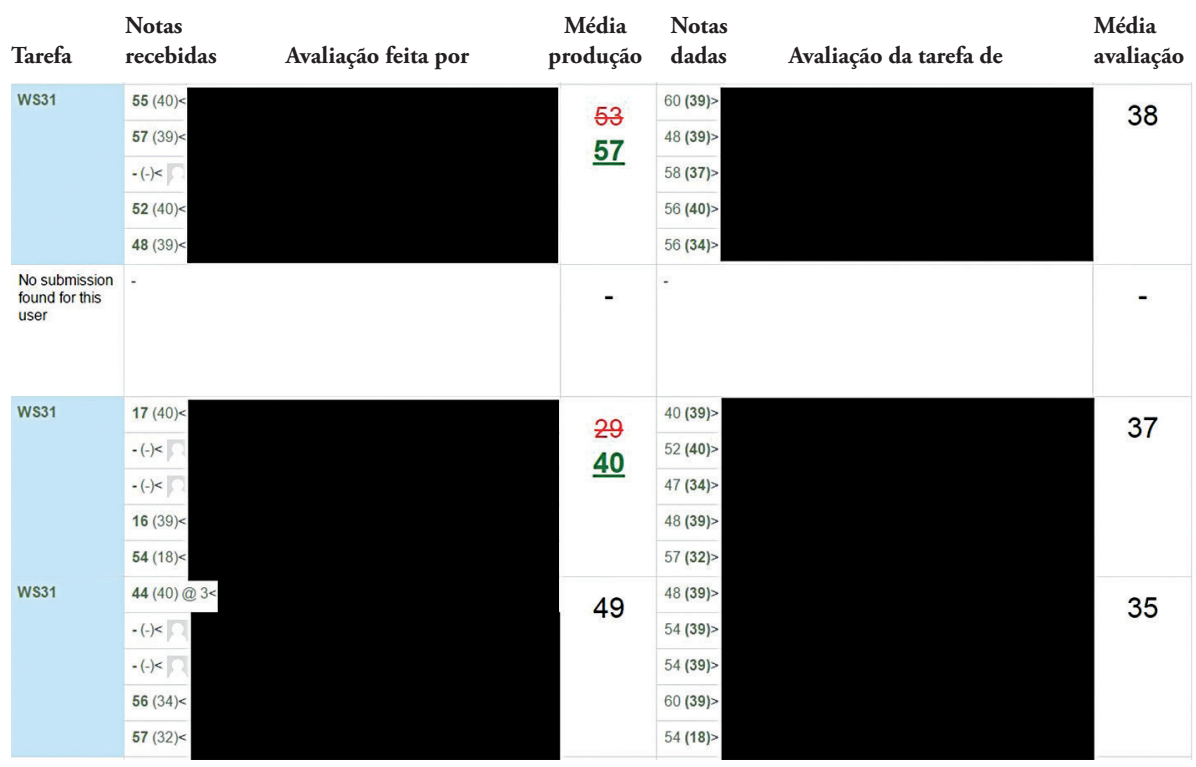

Fonte: Alemão I, 1 Semestre de 2014.

O caso mais complexo ocorre quando os critérios de avalição foram aparentemente aplicados de modo coerente com sua descrição, mas essa aplicação não corresponde 
àquilo que o próprio professor formulador desses critérios faria com base neles. Numa visada wittgensteiniana, uma razáo para esse aparente descompasso está no fato de que um conceito não traz embutido em si, analiticamente, todas as possibilidades de sua aplicação (como exigiria a tradição mainstream, seja na filosofia da linguagem ou na linguística aplicada). O professor experiente saberá quando deve afastar-se da aplicação quase automática do critério elencado, mas o aluno, sujeito em formação por excelência, não tem ainda essa flexibilidade, nem autoridade ou segurança para tanto. Retomando o trecho das Investigaçóes que foi colocado como epígrafe deste artigo, o problema aqui pode estar não no acordo nas definiçóes (por mais que o professor possa ter dificuldades em elencar os critérios de modo objetivo e de fácil aplicação), mas também ou, sobretudo, nos juízos que os alunos podem fazer com base nesses critérios:

Da compreensão pela linguagem faz parte não apenas um acordo nas definições, mas também (por estranho que pareça) um acordo nos juízos. Isso parece abolir a lógica, mas não o faz. - Uma coisa é descrever os métodos de medição, uma outra é obter e exprimir os resultados da medição. Mas aquilo que chamamos de "medir" é determinado também por uma certa constância nos resultados. (WITTGENSTEIN, 2009, p.94-96 [IF, \$242]).

Nos desdobramentos que tem procurado dar à terapia filosófica do último Wittgenstein, rumo a uma pragmática filosófica e uma epistemologia do uso, Arley Moreno aprofunda com muita propriedade essa questáo:

A descrição do uso mostra que [...] a significação [...] não se reduz à definiçấo a priori do sentido, mas diz respeito ao conjunto de suas aplicaçóes. [...] A definição de uma regra de sentido não permite sempre a antecipação, pelo puro pensamento, de todos os casos de sua aplicação, e tampouco pró́be aplicaçóes que venham a exprimir critérios diferentes. Assim, na relação analítica, o pensamento do sentido se exprime na aplicação, e não in vitro, sendo dado que o sentido não é independente da aplicação que dele se faz - da mesma forma, de resto, que na relação sintética a priori do sentido. [...] Em não sendo as aplicaçóes jamais inteiramente previsíveis, abre-se um espaço cuja exploração poderá trazer novas informaçōes. (MORENO, 2011, p.64-65).

Retenhamos algumas implicações dessa relação umbilical entre o sentido e a aplicação do conceito, para os propósitos do Laboratório. Em primeiro lugar, devese aceitar como natural que qualquer descrição prévia dos critérios de avaliação será "imperfeita", na medida em que não garantirá, por si só, uma aplicaçáo adequada por parte dos aprendizes. Mas tal "imperfeiçâo" diz respeito a um ideal inatingível que, exatamente por não condizer com o que ocorre na prática concreta da linguagem, deve ser abandonado, a exemplo da sugestão do Wittgenstein das Investigaçôes em 
relação ao seu antigo ideal de "pureza cristalina da lógica" no Tractatus: por não prever o atrito, um tal ideal não nos permite caminhar, devendo, portanto, ser abandonado em prol do "solo áspero" de nossas práticas (WITTGENSTEIN, 2009, p.51 [IF, $\$ 107])$. O raciocínio pode ser ampliado para muito além do Laboratório do Moodle, valendo também para todo e qualquer sistema de avaliação baseado, em última instância, em quantidade, com aplicação quase automática de "critérios de qualidade" organizados como se fossem planilhas eletrônicas - uma metodologia muito presente nas práticas de avaliação acadêmica atual, no país e fora dele. Nessas abordagens, o conceito de transparência acaba sendo usado de modo abusivo, na medida em que se pressupóe que critérios de avaliaçáo claros seriam condiçáo não apenas necessária, mas também suficiente para se alcançar a objetividade e, com isso, a adequação nas avaliaçôes concretas. Retomando a discussão anterior, podemos concluir que o problema maior reside na segunda premissa, posto que, como lembra Wittgenstein no trecho supracitado, "uma coisa é descrever os métodos de medição, uma outra é obter e exprimir os resultados da medição" (WITTGENSTEIN, 2009, p.94 [IF, \$2 242]).

O filósofo da educação britânico Paul Standish também lança mão da obra tardia de Wittgenstein, com base em tópicos diferentes dos aqui discutidos, em sua crítica à cultura atual de auditoria e prestação de contas (accountability) no setor da educação, sobretudo no tocante à ideia de que seria possível definir a priori critérios de qualidade capazes de diferenciar objetivamente as boas das más práticas pedagógicas (STANDISH, 2012). Em encontro com Grupo de Pesquisa na Faculdade de Educação da USP (16/09/2014), Standish reafirmou sua convicção de que "avaliação é um processo contínuo", de modo que "temos uma ideia razoável do vem a ser um bom ensino", através de "processos informais" e "avaliaçôes tácitas". ${ }^{6}$ O que é dito por Standish pode ser parcialmente correlacionado à questão da aplicação enfatizada por Moreno: se o sentido do conceito depende do conjunto de suas aplicaçóes, a definição prévia e transparente dos critérios de avaliação fornecida no Laboratório do Moodle pode ser um ponto de partida e de referência, mas não dará conta, a priori, de todos os casos possíveis. Somente com a gradativa internalizaçáo desses critérios pelos aprendizes começará a diminuir, gradativamente, o descompasso entre a aplicação dos mesmos critérios por alunos ou professor e, com isso, a necessidade desse último fazer intervençóes diretas nas avaliaçôes interpares. Note-se que, ao internalizar uma norma que era inicialmente externa, o aluno não terá perdido sua autonomia nem deixado de lado as "forças centrípetas" da inovação linguística. Terá pura e simplesmente aprendido a se movimentar de forma mais adequada dentro dos limites e padróes da LE, tais como apresentados nos materiais didáticos e monitorados pelo professor em seu acompanhamento do desempenho em suas classes.

\footnotetext{
6 Cito com base em minhas anotações pessoais, da conversa em inglês com cerca de quatro horas de duração.
} 
O lado positivo da avaliação interpares reside exatamente na possibilidade de o aprendiz aplicar concretamente os critérios fornecidos, tomando-os com válidos. Assim, ao cabo de um certo número de aplicaçóes, terá provavelmente convivido com "uma certa constância nos resultados" e, com isso, criado um repertório individual que o deixará cada vez mais perto de um uso adequado em situaçôes futuras - até mesmo com uma certa flexibilidade para dar conta de situaçôes não previstas na descrição dos critérios tout court. É isso o que ocorre com a proposta de sistematização da escrita contida no material didático Blaue Blume (EICHHEIM et.al., 2006) e sua mobilização no Laboratório do Moodle, tal como praticado em meus cursos de alemão no CEL/ Unicamp.

Diferentemente da grande maioria dos materiais didáticos para o ensino de alemáo no nível básico disponíveis no mercado, e quiçá também de parte das abordagens contemporâneas que prescindem de livro didático, ${ }^{7}$ Blaue Blume trabalha a questão da escrita de modo direcionado e sistemático, retomando o tópico em várias de suas 54 unidades, que recobrem os níveis A1-B1 do Quadro Europeu Comum para o Ensino de Línguas (OLIVEIRA, 2006, para uma caracterizaçâo desse diferencial). A explicitação mais clara dessa abordagem como um todo está na Unidade 43 (Alemáo V no CEL/Unicamp), onde se propóem sínteses do tema apresentado (relato de vida de uma pessoa com problemas de alcoolismo) usando diferentes alternativas de construção textual: em primeira pessoa e registro coloquial; ou na terceira pessoa e registro mais formal (EICHHEIM et. al 2006, p. 269). Um pouco mais adiante, a metodologia de escrita propriamente dita é sintetizada em seus diferentes passos (EICHHEIM et. al 2006, p. 272):

1) coleta do vocabulário pertinente;

2) a - estruturação do tema em tópicos relevantes; b - organização temporal;

3) formulação: primeiramente em oraçóes diretas (estilo paratático), agregando em seguida conjunçóes e demais elementos de ligação;

4) revisão, levando em conta os diferentes modelos de organização sintática e os elementos de coesão utilizados (além de aspectos mais pontuais como ortografia etc.).

Para o exemplo a seguir, interessam, sobretudo, os passos 3 e 4, que colocam grandes dificuldades para os aprendizes brasileiros de alemão, idioma cujas regras de colocação divergem significativamente das do português. $\mathrm{O}$ modelo em questão já estava posto

\footnotetext{
Como exceção, cabe mencionar propostas de ensino de escrita em LE baseadas nos gêneros acadêmicos mais relevantes, um campo de pesquisa que vem ganhando destaque no processo de internacionalização das universidades. Nesses casos, no entanto, o trabalho se dá num nível de proficiência mais avançado, a começar pelo A2 ou, mais provavelmente, pelo B1.
} 
em momentos anteriores da progressão didática de Blaue Blume, dentre outros na Unidade 8 (atividades 13a e 13b, 15; p. 48-49; Alemáo I) e na Unidade 38 (atividade 16, p. 242; Alemáo V), por exemplo. No Laboratório do Moodle, esse roteiro para a elaboração de textos escritos é retomado em diversas tarefas, mesmo onde isso não é trabalhado de modo explícito no material didático propriamente dito. É esse o caso de nosso exemplo, que parte de um tema tratado no nível de Alemáo IV, com base na Unidade 29 em Blaue Blume (Tema da Unidade: Nossa relação com a morte) e fornece, como modelos para a produção dos próprios alunos, alguns textos curtos publicados pelo jornal Die Zeit em 2007, com respostas de personalidades alemás à pergunta "como gostaria de morrer?". ${ }^{8}$ A tarefa prevê: 1 - leitura dos textos fornecidos como modelo; 2 - escrita baseando-se nesses modelos, com a seguinte observação minha (que traduzo do alemão):

Importante: É mais fácil entender um texto escrito do que escrever. O estilo dos textos próprios deve ser autêntico, o que significa que deve-se trabalhar com estruturas e vocabulário compatíveis com o nível do curso. Para isso, o mais indicado é escrever em frases curtas e diretas. Cá e lá, pode-se consultar o dicionário bilíngue ou extrair uma ou outra expressão dos textos usados como modelo. Mas essas palavras devem ser compatíveis com o restante do texto. (Instruçóes para a tarefa WS29 no Alemáo IV).

Retenhamos um trecho de comentário feito na avaliação interpares dessa tarefa (Figuras 6 e 7, abaixo). Percebe-se que o avaliador apontou uma série de aspectos formais que vinham sendo enfatizados no curso, demonstrando com isso não apenas ter internalizado as respectivas regras, como também ser capaz de refletir sobre elas, com observaçóes muito pertinentes. Na Figura 7 , o texto à esquerda mostra a tarefa individual que foi avaliada no comentário em destaque (Figura 6), com minhas marcaçóes de correção e um breve comentário, elogiando a qualidade do texto, em seu conteúdo, e observando que faltou uma revisão dos aspectos formais. Na mesma Figura 7, o texto à direita, no final, traz um brevíssimo comentário elogioso ao desempenho do aluno que fez a avaliação (grafado em azul, como nas correçóes). Note-se ainda que, no PDF com retorno geral para a classe disponibilizando após o fechamento da tarefa, de onde foram extraídos os trechos dos exemplos, estão também transcritos os comentários do avaliador (em fonte de cor diferente). Adoto esse procedimento apenas esporadicamente, quando há exemplos que possam interessar não apenas às partes diretamente envolvidas, mas também à turma toda, na condição de modelo, como no caso em tela.

8 Versão eletrônica disponível em: <http://www.zeit.de/online/2007/13/bildergalerie-sterben>. Acesso em: 18 mai. 2015. Atualmente, apenas o primeiro dos sete textos listados está disponível para leitura sem registro no site. Tarefa adaptada para o Moodle a partir de proposta de Thomas Johnen, entáo Leitor do DAAD no CEL/Unicamp. 
Figura 6 - Avaliação interpares: instruçóes

\section{Aspecto 4}

Percebe-se que houve preocupação com aspectos formais, tais como a pontuação, a posição dos elementos na oração etc.?

- Se você acha que algum aspecto deixa a desejar, faça uma observação no respectivo campo, como: "você não colocou vírgula" ou "o verbo na oração subordinada vem no final", "problema de conjugação/declinação" etc.

- Não precisa comentar todos os detalhes, apenas aquilo que for muito característico e acabar comprometendo a qualidade do texto.

Nota

$3 / 5$

\section{Comentário}

"Ich weiß nicht, wie ich sterben will, aber ich weiß, wie ich sterben nicht will."

Creio que essa construção não seja possivel. O autor parece querer ter dado ênfase ao "nicht will", mas o alemão é rígido e pede "wie ich nicht sterben will".

"Um die Wahrheit zu sagen, ich will nicht sterben."

A expressão "Um die Wahrheit zu sagen"ocupa a primeira posição, ou seja, o verbo devia vir logo em seguida na $2 a$ posição. "Um die Warheit zu sagen, will ich nicht sterben."

"Ich möchte, dass ich und meinen Liebsten für immer zusammen leben können." meine Liebsten está no nominativo (é o sujeito), não devia estar flexionado.

"Dass alle irgendwann sterben, ich zwar weiß, aber an den Tod zu denken schmerzt."

De novo uma expressão ocupando a primeira posição, deslocando o verbo para a posição errada. Fora isso, o verbo não está conjugado. Creio que o melhor seria "Dass alle irgendwann stirbt, weiß ich zwar, aber an den Tod zu denken

schmerzt." Creio que aqui "an den Tod zu denken" realmente só ocupe uma posição (como sujeito oracional no infinitivo).

"Ich hoffe, dass ich lange und gesund leben."

Verbo não conjugado -> "Ich hoffe, dass ich lange und gesund lebe."

"Am Ende ich nicht allein sein möchte."

Verbo deve vir na $2 a$ posição em oração principal: "Am Ende möchte ich nicht allein sein."

Fonte: Alemão IV, 10 Semestre de 2014.

O comentário que vem no início da Figura 6 (e na Figura 7, grafado em verde), ilustra bem alguns dos tópicos discutidos nas seçóes anteriores: "Creio que a construção não seja possível. O autor parece querer ter dado ênfase ao 'nicht will', mas o alemão é rígido e pede 'wie ich nicht sterben will'". Do ponto de vista da comunicação, fica evidente que não houve dificuldade de entendimento, $\mathrm{o}$ enunciado é eficiente nesse sentido (mesmo que talvez cause estranheza a um falante nativo). Mas estão em jogo também aspectos formais, que o revisor aponta com propriedade nesse e nos outros comentários. Note-se também que tais aspectos são retomados de modo sistemático no material didático, como na supracitada síntese da Unidade 43 (EICHHEIM et.al., 2006, p. 272, com remissão às páginas onde os respectivos tópicos foram tratados ou sintetizados: p.167, 235, 241, 242; 211, $253,271 ; 216)$. Daí a observaçáo de que "o alemão é rígido e pede [...]". Aqui, o aluno avaliador incorpora um parâmetro que lhe era originalmente externo, e o faz de forma plenamente autônoma, mesmo ainda estando longe de uma proficiência avançada na LE. 
Figura 7 - Avaliação interpares: correção e comentários

\begin{tabular}{|c|c|}
\hline $\begin{array}{l}\text { Wie wollen Sie sterben? } \\
\text { Ich weiß nicht, wie ich sterben will, aber ich weiß, } \\
\text { wie ich nicht sterben nicht-will. Um die Wahrheit } \\
\text { zu sagen, will ich will nicht sterben. Ich möchte, } \\
\text { dass ich und meinen Liebsten für immer } \\
\text { zusammen leben können/könnten. Dass alle } \\
\text { irgendwann sterben, weiß ich zwar weiß, aber an } \\
\text { den Tod zu denken schmerzt. Ich hoffe, dass ich } \\
\text { lange und gesund leben. Bevor ich sterbe, will ich } \\
\text { dasie Leben genießen. Am Ende möchte ich nicht } \\
\text { allein sein möchte. } \\
\text { Guter Text, ich gratuliere! Aber es fehlte eine } \\
\text { Revision von kleinen, schon bekannten Details. } \\
\text { "Ich weiß nicht, wie ich sterben will, aber ich weiß, wie } \\
\text { ich sterben nicht will." } \\
\text { Creio que essa construção não seja possivel. O autor } \\
\text { parece querer ter dado ênfase ao "nicht will", mas o } \\
\text { alemão é rígido e pede "wie ich nicht sterben will". }\end{array}$ & $\begin{array}{l}\text { "Am Ende ich nicht allein sein möchte." } \\
\text { Verbo deve vir na 2a posição em oração principal: "Am } \\
\text { Ende möchte ich nicht allein sein." } \\
\text { Das sind alle sehr qute und sachliche Kommentare. } \\
\text { superbe Revisionsarbeit!! Vergleiche mit meinen } \\
\text { eigenen Korrekturen. }\end{array}$ \\
\hline
\end{tabular}

Fonte: Alemão IV, 1º Semestre de 2014.

O efeito dessa tarefa do Laboratório (WS29) nas atividades de escrita subsequentes também se mostrou positivo, com o reconhecimento generalizado da pertinência de observaçóes como as citadas acima e da importância dos tópicos tratados. Na condição de avaliadores, os alunos tiveram a oportunidade de aplicar a cinco diferentes textos os critérios fornecidos pelo professor e, com isso, testar os limites de aplicaçáo desses critérios. Podemos concluir, ecoando Wittgenstein nos comentários a seu Dicionário, que a consciência gramatical e textual dos alunos foi aguçada pelas atividades de escrita e revisão interpares desenvolvidas no Laboratório, com a subsequente correção pelo professor - o que era um dos objetivos de aprendizagem. Tal objetivo faz parte da preparaçáo para o jogo de que fala Wittgenstein nas Investigaçóes, envolvendo tanto a explicitaçáo das regras como vários exemplos e tentativas de sua aplicaçáo. O jogo em si virá com o uso da escrita em situaçóes autênticas na LE, ainda que, de certo modo, ele já seja jogado em sua preparação. Poderíamos explorar um pouco mais o exemplo fornecido ou mesmo agregar outros, para aprofundar a discussão. Tendo em vista as limitações de espaço e considerando que questôes de ordem prática/ empírica são apenas um dos aspectos do argumento, deixarei tal aprofundamento para oportunidades futuras, caso o tópico venha a despertar o devido interesse.

De resto, seja também registrado que a metodologia proposta é trabalhosa, por mais que a ferramenta Laboratório tenha incorporado alguns mecanismos de automatização muito úteis. No caso específico dos meus cursos, os alunos têm de trabalhar bastante, i.e., há um grande volume de escrita e leitura/avaliação - o que é condizente com o princípio de que a aquisição de competências linguísticas demanda um certo grau de variação e repetição. Para o professor, o volume de trabalho também é significativo. Além de demandar a explicitação de seus próprios critérios de avaliação, com a respectiva 
relação de pesos para cada tarefa, exige muita atenção a detalhes de configuração e supervisão do cronograma de trabalho. Com o tempo, porém, certos parâmetros vão-se firmando como adequados e permitem a reutilização em cursos futuros com os mesmos conteúdos e objetivos. No caso de programas que atendem a um grande número de alunos, eventualmente com várias turmas de mesmo nível, a equação pode se inverter, levando a uma otimização do tempo investido como resultado geral, pela mudança de escala. Nesses casos, abre-se a possibilidade de avaliação por amostragem e correção de desvio, com retorno aos alunos caracterizando diferentes perfis de resoluçáo da tarefa e dificuldades típicas como, por exemplo: trabalhos exemplares, ou característicos de certo padrão ou tendência da(s) turma(s); trabalhos bons ou fracos em relação a aspectos específicos, ou outros que ilustrem estratégias de escrita pouco aconselháveis (por não conduzirem a resultados aceitáveis) etc. (Figura 1, acima). Aqui, pode-se afirmar que parte dos problemas levantados por Wittgenstein em relação à correção interpares pode ser superada, na medida em que os mecanismos de inteligência artificial embarcados no Moodle permitem detectar os desvios do padrão e fazer uma análise dos diferentes tipos de caso, sem ter que avaliá-los todos nem cada tarefa individualmente, e sem que cada aluno tenha que revisar "os textos de todos seus colegas". A despeito das diferentes implicaçóes para cada contexto específico, a ferramenta Laboratório de Avaliação do Moodle certamente merece ser levada em conta onde houver possibilidade de seu uso, tendo em vista seu potencial de inovação em nossas práticas pedagógicas.

\section{Observações finais}

$\mathrm{Na}$ introdução a este artigo, apontei para a multiplicidade de camadas que seriam abordadas, por influência das questôes sobre as quais tenho refletido nos últimos tempos. Espero que o leitor tenha conseguido acompanhar sem maiores problemas as passagens de uma camada a outra, e que os principais argumentos da reflexão mais básica, de caráter epistêmico, tenham sido ilustrados, em alguma medida, pelos exemplos apresentados - ainda que isso não seja trivial. Mesmo que esse objetivo parcial porventura não tenha sido alcançado, talvez o leitor possa tirar proveito da discussão mais concreta de questóes de implementação e uso do Laboratório de Avaliação no Moodle. O campo de utilização em si, ensino de LE em nível básico, coloca algumas restriçōes àquilo que pode ser feito com essa ferramenta, na medida em que o meio de expressão também é objetivo de aprendizagem. Outro campo, onde o horizonte de possibilidades se amplia de forma considerável, diz respeito ao trabalho com professores em formação, notadamente no aperfeiçoamento de sua competência como avaliadores - um aspecto cuja importância em hipótese alguma deveria ser subestimada. Talvez resida aí o maior potencial do Laboratório. Mas mesmo no ensino de LE em nível básico, é possível colher alguns frutos, desde que nos lembremos sempre de que a definição de bons critérios não dará conta, por si só, de todos possíveis casos futuros - se é no conjunto das aplicaçóes que o conceito se desdobra de fato. 


\section{AUTONOMY AND EXTERNAL PARAMETERS: INCOMPATIBLE? REPLACING THE QUESTION WITHIN THE MOODLE WORKSHOP, IN THE COMPANY OF WITTGENSTEIN.}

- Abstract: I retake here the later philosophy of Wittgenstein and his conception of language to reflect on some central concepts and roles in language teaching, which are often treated dichotomously: autonomy vs. external parameters, focus on student vs. teacher, classroom learning vs. virtual learning centers, subjectivism vs. transparency/objectivity in evaluation. As an antidote to eventual generalizing excesses of methodological approaches or explanatory models, I propose that we assume a concrete perspective of the teacher in finding effective solutions to intervene in the learning process. I then give examples of how this attitude shows itself in the promotion of writing skills in basic German courses with the courseware Blaue Blume, using the Moodle Workshop for this purpose. I also discuss some technical details in the use of this tool and its tweaking options.

- Keywords: Autonomy. Norm. Writing. Peer evaluation. Virtual learning centers. Wittgenstein.

\section{REFERÊNCIAS}

BORGES, E.F.V.; PAIVA, V.M. Por uma abordagem complexa de ensino de línguas. Linguagem \& Ensino, Pelotas, v.14, n.2, p. 337-356, jul./dez. 2011. Disponível em: <http:// www.veramenezes.com/Borges_Paiva.pdf>. Acesso em: 18 mai. 2015.

CASTILHO, A.T. A gramática na ponta da língua (e na linguística da Unicamp) Jornal da Unicamp, n. 328, 26/6-2/7/2006, p. 4-5. Disponível em: <http://www.unicamp.br/unicamp/ unicamp_hoje/ju/junho2006/ju328pag4-5.html>. Acesso em: 18 mai. 2015.

CLARK, K.; HOLQUIST, M. Mikhail Bakhtin. São Paulo: Perspectiva, 1998.

EICHHEIM H. et al. Blaue Blume. Campinas, Ed. da Unicamp, 2006.

CENTRE INTERNATIONAL D'ETUDES PÉDAGOGIQUES (CIEP). European Profiling Grid. 2013. Disponível em: <http://www.epg-project.eu/>. Acesso em: 18 mai. 2015.

GLOCK, H.J. Dicionário Wittgenstein. Rio de Janeiro: Jorge Zahar, 1998.

KUHN, T. A estrutura das revoluçóes científicas. São Paulo: Perspectiva, 1997.

MORENO, A. La description grammaticale et sa fonction transcendantale. In: MORENO, A.; SOULEZ, A. (Org.). Grammatical ou transcendantal?. Paris: L'Harmattan, 2011. p. 43-71.

NEWBY, D. et al. Europäisches Portfolio für Sprachlehrende in Ausbildung: Ein Instrument zur Reflektion. Graz, Áustria: Council of Europe Publishing, 2008. Disponível em: <http:// archive.ecml.at/mtp2/publications/C3_EPOSTL_D_internet.pdf>. Acesso em: 18 mai. 2015. 
OLIVEIRA, P. Escrita em ambientes eletrônicos: colaboração e avaliação inter-pares no Moodle. In: IX CONGRESSO BRASILEIRO DE LINGUÍSTICA APLICADA, 9., Rio de Janeiro, 2012. Anais eletrônicos... Rio de Janeiro: ALAB, 2012. v.1. p.1-18. Disponível em: $<$ http://www.alab.org.br/images/stories/alab/CBLA/ANAIS/temas/19_14.pdf>. Acesso em: 18 mai. 2015.

À procura da flor azul no ensino da língua alemã. Projekt, Curitiba, v. 44, p.13-23, 2006. Disponível em: <http://www.unicamp.br/ paulocel/leituras/Flor_azul.pdf>. Acesso em: 18 mai. 2015.

. Prefácio do Dicionário para escolas primárias: comentário introdutório e tradução. In: GOTTSCHALK, C. Wittgenstein e a educação, 2015. No prelo. Manuscrito com 16 páginas.

REIS, F. O Dicionário para escolas primárias de Ludwig Wittgenstein, 2015. No prelo. Manuscrito com 25 páginas.

SCHLEIERMACHER, F.D.E. Sobre os diferentes métodos de tradução. In: HEIDERMANN, W. (Org.). Clássicos da teoria da traduçáo. Florianópolis: Ed. da UFSC, 2010. p. 38-101.

SCHRAM, K. Pendelschwung zurück?: DaF-Lehrkompetenz im Fokus. In: XV CONGRESSO DA ASSOCIAÇÃO LATINO-AMERICANA DE ESTUDOS GERMANÍSTICOS, 15. Curitiba, 2014. Caderno de resumos... Curitiba: Quadrioffice, 2014.

STANDISCH, P. 'THIS is Produced by a Brain-Process!' Wittgenstein, Transparency and Psychology Today. Journal of Philosophy of Education, West Sussex, v. 46, n. 1, 2012.

VILLALOBOS, I. Análise da fundamentaçáo dos materiais didáticos do programa Ler e Escrever da Prefeitura de Sáo Paulo/SP. 2014. 265f. Tese (Doutorado em Educação) Faculdade de Educação, Universidade de São Paulo, São Paulo, 2014.

WITTGENSTEIN, L. Philosophical Investigations = Philosophische Untersuchungen . Malden; Oxford: Wiley-Blackwell, 2009. (Investigaçôes Filosófica = IF).

Culture and Value: A Selection from the Posthumous Remains. London: Blackwell, 2006. $($ Cultura e valor $=\mathrm{CV})$.

Letzte Schriften. Oxford: Blackwell, 1982. (Últimos escritos = UE).

$($ Dicionário $=\mathrm{D})$.

Wörterbuch für Volksschulen. Viena: Verlag Hölder-Pichler-Tempsky, 1977. Über Gewißheit = On Certainty. Oxford: Blackwell, 1975. (Da Certeza = DC). Tractatus logico-philosophicus. Londres: Routledge: Kegan Paul, 1961. (T). 